\title{
PREVENTION OF SUBSTANCE ABUSE IN CHILDREN AND ADOLESCENTS: EVIDENCE BASED PRACTICE APPROACH
}

\author{
Enedina Hasanbegović-Anić, Aneta Sandić, Sabina Alispahić
}

\begin{abstract}
Adolescence is a developmental period during which, most commonly, use of substances begins. Thus a majority of preventive initiatives target child population and youngsters. With regards that many traditional and widely utilized preventive programs turned out to be ineffective, scientists have put much effort into the development of much more efficacious, contemporary approaches in evidence-based prevention during the last decades. Although the number of available evidence- based preventive programs significantly raised during the past several years, there are still obstacles in recognition of importance in their implementation, as well as obscurities about what that term actually stands for. This paper provides a review of most important scientific insights about substance abuse in the population of youngsters, which are the foundation of good practice in the field of prevention, as well as a more specific definition of programs that bear "evidence-based" label. Key traits of efficacious substance abuse prevention programs targeting family, school, and community are presented, as well as examples of good practice.
\end{abstract}

Keywords: substance abuse in children and adolescents, preventive programs, evidence-based approaches 


\section{INTRODUCTION}

Regardless numerous preventive initiatives substance abuse still remains an important public health issue worldwide and it significantly accounts to a frequency of morbidity and mortality in the population of abusers (Hemovic, Lac \& Crano, 2012; Lopez, 2006). Namely, many traditional and widely applied preventive programs proved to be inefficacious, thus much effort has been put into development and testing of programs efficacious in the areas of risk prevention, that is behaviors associated with the use of substances (Catalano, Haggerty, Hawkins \& Elgin, 2011).

Field of prevention evolved into scientific discipline in the last decades and it accounts to a better understanding of epidemiology, etiology, and complexity of behaviors associated with substance abuse in a significant manner. This involves identification of initiation patterns, as well as a progression towards more severe levels of substance abuse. Those insights resulted in directing a majority of preventive initiatives towards a child and adolescent population (Griffin \& Botvin, 2010), and defining key concepts and program methods in contemporary evidence-based preventive programs (Sussman \& Ames, 2008).

This paper provides a review of most important insights related to use and abuse of substances in adolescent population which proved to be the foundation in the field of prevention. Contemporary preventive terminology in mental health is presented as well, terminology officially used among scientists and practitioners in the field of substance abuse. More detailed definition of evidence-based preventive methods are portrayed as well. Traits of efficacious preventive programs targeting family, school, and community, as well as examples of good practice are noted at the end of the paper. 


\section{EPIDEMIOLOGY AND RISKS / PROTECTIVE FACTORS: IMPLICATIONS FOR PREVENTION}

Adolescence is a developmental period that is most frequently marked by experimentation that is use and abuse of various substances (Kandel, 2002). Most research conducted in Western countries pointed out that until the age of nineteen about $90 \%$ of young people tasted the alcohol, $60 \%$ smoked cigarettes, 50\% used cannabis and $20 \%$ tasted other street drugs as inhalants, stimulants, hallucinogens or opiates (Coughlan, Doyle \& Carr, 2006). Epidemiological research consistently proves that prevalence of tobacco, alcohol and illegal drugs use quickly rises from early towards late adolescence, with the peak at the turn towards younger adult age, after which it declines (Jochman \& Fromme, 2010). The most frequent developmental model which leads towards abuse of substances involves the beginning of the use of legal substances (tobacco and alcohol), then cannabis, and in the end the other illegal substances. Mentioning this it is important to note that at every next step of developmental progression the risk of developing psychological disorders related to substance abuse gets higher (Griffin \& Botvin, 2010). Most adolescents who use substances will not develop severe problems; however, some less than $10 \%$ youngsters from this group will continue their problematic use in adult age (Fagan, 2006). The beginning of substance use in early adolescence (before age of fifteen) is strongly connected with higher level of substance abuse (Arthur, Hawkins, Pollard, Catalano \& Baglioni, 2002; Swendsen et al., 2012), and many health issues, as well as psychological and social consequences later on during lifetime. This includes mortality, problems with somatic and mental health, violence, difficulties in the interpersonal field, adaptation issues in the family and academic and working milieu (Newcomb \& Locke, 2005).

In accordance with contemporary findings the most efficacious preventive programs are based on relevant etiological psycho-social theories of use and abuse of substances, and are aimed at main risk and protective factors (Griffin \& Botvin, 2010). Thus, maintainable prevention models must at the same time be focused on multiple risk and protective factors originating from different domains which include personal traits, family, peers, school and community (National Crime Prevention Centre, 2009), as well as developmental periods when each of the named factors stabilizes as predictor of substance use (Hawkins, Catalano \& Miller, 
1992). As relation between the number and type of risk and prevention factors influences the risk of individual's beginning of use and abuse of substances, the main goal of preventive programs is to raise the influence of protective factors and reduce or remove influence of risk factors in order to prevent or postpone the beginning of substance use, that is to reduce the level of use of noted substances in the population of youngsters (Hawkins, Catalano \& Arthur, 2002). It is also important to note that many of the risk factors in the area of use and abuse of substances represent predictors of other behavioral issues such as delinquency, risky sexual behavior, and school dropout, thus comprehensive preventive programs aimed at risk and protective factors most likely may prevent even those problems in the population of youngsters (Hawkins, Catalano \& Miller, 1992).

Preventive programs may be conducted in different social milieus, and so far many efficacious programs targeting family, school and community have been developed. Those can be combined or used selectively. Research evidence shows that multicomponent preventive programs combining two or more effective programs, such as family and school programs may even be more efficacious than single programs aimed solely at school, family or community (National Institute on Drug Abuse, 2003).

\section{CONTEMPORARY PREVENTIVE TERMINOLOGY}

Traditionally, researchers and practitioners divide all interventions in the field of mental health into primary, secondary and tertiary prevention. However, during that last two decades, there is new terminology being used which additionally differentiates various levels of preventive interventions in this area (Sussman \& Ames, 2003). The significant contribution to a conceptual improvement in the field of prevention in mental health was provided by Mrazek and Haggerty (1994), accenting that traditional, medical preventive model is not equally adequate for the mental health issues as it is meant for medical disorders. Those authors suggested an alternative to the medical model of prevention introducing the model of spectrum interventions in mental health, within whose frame interventions are differentiated into prevention, treatment, and maintenance of contemporary state.

Prevention includes three levels of intervening: universal, selective and indicated prevention. This nomenclature is nowadays utilized among researchers and participants who work in the field of prevention of use and abuse of substances. Each level of intervention in the frame of prevention 
aims at different levels of risk which are present in the target populations. Universal preventive programs are designed for the general population, with the aim to hold back or postpone some state (for example programs targeting all pupils at school). Secondary preventive programs are aimed at addressing parts of a population under greater biological, psychological and social risks for development of psychological disorders than it is the case with an average population (e.g. children and adolescents whose parents use substances or children and adolescents with lower academic achievements). Indicated preventive programs are applicable to those groups which already express subclinical signs or symptoms of development of the disorder (e.g. experiments with substances, the initial stadiums of involvement into highly risky behaviors) (Mrazek \& Haggerty, 1994; Sloboda, 2009).

\section{WHAT ARE EVIDENCE BASED-PROGRAMS?}

In the past two decades there is a significant increase in available preventive programs aimed at improvement of emotional, behavioral and social functioning of children and adolescents, and great effort has been put in defining standards of good evidence-based practice and ways of achieving it (Forman, Olin, Hoagwood Crowe \& Saka, 2009). The principle of evidence-based practice promotes utilization of empirically supported preventive programs supported by research findings which provide evidence about the benefits and predictable outcomes, and which are conducted within valid national laws and policies (Ysseldyke et al., 2006).

Although the term "evidence-based program" became common in preventive science and practice there are still obstacles in recognition of the importance of their implementation as well as obscurity in understanding what is all that is meant under this term? Namely, also the existing terminology may lead to confusion because different terms are being used interchangeably, such as "programs that promise", "evidence-based programs" and "efficacious programs". Different agencies and research groups also adopted different criteria for identification whether a certain program is based on evidence or it is not, thus encouraging the application of efficacious and effective preventive programs (Kyler, Bumbarger \& Greenberg, 2005).

Efficacy of a preventive program is determined at the grounds of results of controlled (experimental or quasi-experimental) research with 
sufficient interior validity, which show that program reliably results with certain positive effects. A preventive program is considered efficacious if identified positive effects have sufficient outer validity that is if it proves that the program is of practical use when applied in different natural surroundings (Hunsley \& Lee, 2010). Thus, evidence-based programs are the ones which, besides proved usefulness in controlled conditions, have a proved effectiveness in real life and within the scientific community, and they are often marked in terms of efficacy (Kyler, Bumbarger \& Greenberg, 2005).

Further on, after it is identified whether a preventive program is efficacious, it is necessary to submit it to critical validation from the side of independent researchers from the given field, what involves methods questioning evaluation and agreement on conclusions about the effectiveness of programs. When a preventive program has been checked out by independent experts and when there is evidence about efficacy, its authors usually provide it for consideration to the licensed agencies or research groups. Those organizations approve preventive programs, what enables other experts in the field to get acquainted with the preventive programs which satisfy the regulated standards (Cooney, Huser, Small \& O'Coonor, 2007).

For example, SAMHSA (The Substance Abuse and Mental Services Administration, 2015), American agency whose mission is to reduce an influence of substance abuse and mental disorders in the community, developed The National Registry of Evidence Based Programs and Practices (NREPP). This data basis contains review of more than 340 evidence based preventive and treatment interventions in the field of mental health and substance abuse, in order to make it easier for interested individuals, organizations and communities to learn more about those programs and practices and make decisions about which kind of interventions would be the most suitable for their issues.

Thus, when a community decides to apply for evidence basedpreventive program, and when addressed experts or organizations choose a certain program that suits the actual needs in a community, it is needed to culturally adjust the program and evaluate its efficacy before it becomes implemented. When the choice about evidence-based programs are being made the critical attitude is of importance, with respect of the fact that all programs that meet criteria for the label "evidence-based" are not equally efficacious. For example, preventive programs that prove to be efficacious in repeated experimental studies, and programs that involve follow up of 
the subjects during the longer period of time, are in general considered to be better than programs evaluated in one or two less rigorous studies (e.g. that utilized quasi-experimental design). Besides this, higher standards are met by those preventive programs that are successfully replicated and evaluated in different surroundings with a wide range of users, and programs that consistently result in a higher power of confirmed effects (National Institute on Drug Abuse, 2003).

\section{Advantages and limitations}

Evidence-based preventive programs are beneficial on multiple levels, and their adequate implementation means a well thought and responsible manner of utilization of limited resources that the community possesses. Namely, implementation of these programs increases the possibility of achievement of the expected outcomes, what also increases benefits in the community, as it is more effective to use limited resources within programs that proved to be efficacious, than taking into account the programs thought to be efficacious or traditionally used programs. Organizations can choose the program from the specter of an increasing number of evidence-based programs, which often offer already prepared material, education of implementations and technical support, instead of directing their resources towards program development. Proved efficacy of evidence-based programs ensures not only greater economic benefits but a greater support of the donors, public policies and members of target populations as well, what altogether may help to find and keep the program users. In the end, those programs as well contain available information about costs estimation and the utility of programs what is of significant importance in times when responsibility and economic factors rule public policies and decisions about the distribution of resources (Cooney et. al., 2007).

However, it is important to accept that evidence-based programs bear some practical limitations. Namely, many of these programs are copyrighted what results in significant costs what is often the main obstacle to their adoption and implementation. Creators of programs often require that organizations buy the program material and that for full implementation, besides the need to possess a certain level of education or certain certificate; personnel must get involved in professional training. Apart from this, there are also requirements that these programs have to be implemented exactly in the manner they have been conceived, what leaves little space for local adaptation. Finally, it can happen that existent evidence-based programs 
are not at the same time suitable for the needs of the target population, an organization that plans their use and/or local community. This usually happens when organizations wish to improve positive outcomes in the target population (e.g. academic success), that is when the aim is not prevention of negative outcomes (e.g. substance abuse, mental illness, violence or delinquency). Namely, in contemporary times we witness a much larger number of evidence-based programs aimed at the problem then promotion of positive developmental outcomes because agencies that sponsor their development in most cases happen to be involved in the solution of some specific mental health issues (Cooney et al., 2007).

\section{Planning and implementation}

The planning process of preventive programs focused on children and adolescents should begin with the evaluation of substance abuse in the community. This includes estimation of nature and range of drug abuse, estimation of risk and protective factors, understanding the influence of cultural milieu on drug abuse and vice versa, estimation of consciousness of given community about the problem and identification and estimation of existing preventive activities. The aim of estimation of existing preventive programs is to identify which programs have been currently conducted, weather clear health standards have been used in the check of the programs during their development, whether programs meet needs of the community and in which range youngsters who are at risk have been encompassed by given programs. Another form of evaluation of evidence-based programs is based on the use of existing data on drug abuse among youngsters and related problems during the time. Data gathered in initial estimation of the condition in some community may serve as the beginning for measurement of change during time. As nature and range of issues related to substance abuse changes in the time it is useful to periodically estimate risk and protective factors in the community, as to ensure that existent preventive programs in an adequate manner meet the needs of the community (National Institute on Drug Abuse, 2003).

\section{PREVENTION TARGETING FAMILY}

Preventive programs may enforce specific family protective factors which increase the possibility of adaptive developmental outcomes in children and adolescents through parental education in various parenting skills. A high number of various preventive programs targeting families 
have been developed by now. They can be divided into two categories. One of them targets only parents that are their enforcement, in order to prevent their child from making contact with substances. These programs include education of parents in the field of specific parental skills which involve upbringing, making family rules, connectedness and communication with children, supervision of child activities, and competence in teaching their children prosocial skills and skills of resisting social pressures and helping children to reduce aggressive and antisocial behavior. Another type of programs is aimed at learning certain skills involving both, parents and children. Those programs' aim is to improve family functioning, communication skills, provide support in establishing family rules about substance use, and teach parents about imposition and implementation of those rules. Interventions targeting parental skills and family connectedness proved to be most efficacious in the reduction or prevention of substance use. However, an important possible limitation of programs targeting families reflects itself in hardships related to involving parents in the program, in particular, young parents who are at the greatest risk of substance abuse (Griffin \& Botvin, 2010).

\section{PREVENTION TARGETING SCHOOL}

Schools are focus of majority of preventive initiatives (Bloom \& Gullotta, 2009) as they enable prolonged approach to nearly complete population of children and adolescents, including specific subpopulations who are under higher risk of use and abuse of substances, such as children and adolescents having behavioral issues, hardships in learning or ones that are under risk of dropping-out school (National Institute on Drug Abuse, 2003). Further on, in comprehensive preventive programs targeting multiple domains of the social milieu of youngsters, schools represent the main coordinating institution and link with families and the wider community (Stigler, Neusel \& Perry, 2011).

\section{Traditional approaches}

Results of numerous research proved that many traditional and widely applied preventive substance abuse programs, that involve providing information about substances, effective education, and alternative programs, although at the first glance assuredly, are not efficacious. Failure of those programs reflects itself in the fact that they are not based on relevant theories and integrated knowledge about aetiological factors, but 
on intuitive suppositions on how to prevent abuse of substances (Schinke, Botvin \& Orlandi, 1991; Foxcroft \& Tsertsvadze, 2011; Thomas, McLellan \& Perera, 2013).

Providing information about substances and noxious effects of their use represents the most common preventive approach which is based on simple cognitive model according to which people make decisions about the use of substances on the basis of their knowledge about their noxious consequences. Some of these programs, aiming at accenting the noxious consequences of substance additionally utilize techniques that provoke fear or moral, that is religious appeals. Affective education is another common approach in prevention and it supposes that encouraging personal affective development (e.g. self-respect, assertiveness etc.) reduces the probability of substance abuse. Alternative programs are conceptualized in the manner that to youngsters they offer various creative, recreative and educative activities, with the suggestion that those activities may be a substitute for behaviors associated with substances use (Botvin \& Kenneth, 2006).

\section{Contemporary approaches}

In the recent decades, much more efficacious school preventive programs on substance abuse issue have been developed and evaluated. They involve resistance to social pressures, normative education, and increase of competence while, within frames of one program, those approaches can be combined (Griffin \& Botvin, 2010).

Approaches based on skills related to resistance to social pressures are based on Bandura's theory of social learning (1977), and on a conceptual model that accents key role of social influence on the side of peers and media in the initiation of use of substances (Botvin \& Kenneth, 2006). The main goal of preventive interventions that follow this approach is to increase consciousness of youngsters about various social influences that support the use of substances and teach them specific skills of efficacious resistance to peer pressure and media to use substances (Botvin, 2000).

Normative education is an approach based on the fact that many adolescents overestimate the prevalence of various substances use in the population of youngsters, what may lead towards views that utilization of substances is taken as normative behavior. Contents of programs and activities based on this approach aim at correction of incorrect normative expectations and beliefs of adolescent population that the use of substances is socially acceptable and not noxious, what is achieved through education of youngsters on actual incidence of substance use through presenting 
research results that were conducted on local and/or national level (Griffin $\&$ Botvin, 2010). Normative education may have a key role in encouraging adolescents to use strategies of resistance to the peers and media. Results of research suggest that absence of a normative component in preventive programs may reduce effects of training in the area of resistance to pressure imposed by peers and social pressures that promote disuse of substances (National Crime Prevention Centre, 2009).

Approaches focused on increasing competencies are some of the most comprehensive programs in the area of prevention of substances abuse and are based on social learning theory (Bandura, 1977) and behavioral problem theory (Jessor \& Jessor, 1977). Within this approach abuse of substances is conceptualized as behavior which is, as a result of complex interaction of numerous personal and environmental risk factors, learned in social context and functionally. Namely, adolescents that have weak personal and social skills may be under higher risk to use substances as an alternative to adaptive strategies facing with, for example, anxiety or low self-esteem. Approaches focused on increasing competencies accent teaching youngsters in a wide spectrum of general life and social skills, such as problem-solving skills and making decisions, cognitive skills of resistance to social pressures, skills in increasing self-control and selfrespect, adaptive coping with stress and anxiety, general social skills and assertiveness. Those skills are taught by applying proved cognitivebehavioral methods, such as teaching, demonstrating, providing feedback, corroboration, behavioral trials, and homework. Most efficacious programs based on those approaches, apart from accepting the application of real life and social skills in situations that are directly associated with substance use, teach young people how to use these skills in coping with many other challenges in daily life (Griffin \& Botvin, 2010; Botvin \& Kenneth, 2006; Schinke, Botvin \& Orlandi, 1991).

\section{Implementation of preventive programs at schools}

In spite of the fact that evidence-based preventive programs targeting schools are available (PAS), research results suggest that the implementation of these programs is insufficient (Forman et al., 2009). Research conducted in the national sample consisting of 1795 public and private schools in the USA (Ennett et al., 2003) revealed that over $80 \%$ of schools conducted some kind of drug abuse prevention, but that only $17.4 \%$ of schools utilized programs that proved to be efficacious methods (e.g. 
interactive approaches), while only $14 \%$ of schools applied for efficacious programs. Also, research results show that even when schools use evidencebased preventive programs, those programs are often being conducted in the manner that does not meet established standards (Hallfors \& Godette, 2002), what results in reduction of positive outcomes, despite established strong effects of programs in conducted studies (Botvin \& Kenneth, 2006).

With time scientists came to the insight that conducting evidencebased preventive school programs appeared to be a complex process which is under influence of a numerous number of personal, organizational and systemic factors. Namely, it is not enough just to offer an efficacious program and guidelines for its implementation as was thought in previous times. In introducing preventive evidence-based programs at schools it is needed to focus effort at factors that are, according to research results, of significant importance for their successful implementation and maintenance, and to strengthen the connection between research and practice. This involves development of support on side of school board and teachers, development of financial resources, enabling higher level training and consultation systems for personal who implements the program, adjustment of preventive program to school goals, programs and policies, ensuring obvious outcomes of programs, and development of strategies of coping with exchange of school personnel and board (Forman et al., 2009).

\section{PREVENTION TARGETING COMMUNITY}

Preventive efforts that wish to revise key aspects of social surrounding which increase the risk of substance abuse demand activities at the level of community. Preventive programs targeting community as a whole by the rule are multi-component and often include combining school preventive programs with media campaigns and activities of public policies and interested organizations in the community. The aim is to enforce prosocial behavior and social norms against substances use. By rule, those programs contain a wide spectrum of activities and accordingly demand significant financial and other resources, as well as good coordination. Realization of program components is often achieved through the cooperation of all interested sides, including parents, schools, experts, and leaders in the community. Research results point out that those programs, if comprehensive and well coordinated, may be efficacious in the prevention of substance abuse in youngsters (Griffin \& Botvin, 2010). 


\section{EXAMPLES OF GOOD PRACTICE}

In the text that follows there are briefly described some of the proven efficacious preventive programs related to substance abuse, ones that are developed for target populations of children and adolescents of various school age in the domain of universal, selective and indicated prevention (Substance Abuse and Mental Health Services Administration, SAMHSA, 2015). It is important to accept that scientists, besides continuous development of new programs at the levels of prevention, also put additional effort in research in order to adjust preventive programs to specific populations with regards to gender, ethnic, race and geographic belonging, and additionally raise their effectiveness.

LST program (Life Skills Training Program) is a universal preventive school program targeting a wide range of risk and protective factors related to abuse of substances, with the aim to prevent the use of tobacco, alcohol, and marijuana. It contains three main components that involve: 1) learning skills related to control over one's own behavior, 2) learning general social skills and 3) learning skills of resistance towards drug abuse and normative education. It is meant for elementary and high school pupils with age range from thirteen to seventeen. It consists of three years lasting preventive curriculum made up of thirty sessions. Fifteen sessions become realized during the first year of the program, ten additional sessions during the second year, and five sessions in the last year of the program. The logical basis of LST application in those time frames comes out from insights about developmental progression of drug abuse, cognitive and psychosocial changes typical for adolescence, increasing domination of influence of peers, and issues related to transit from elementary to high school. Implementations of the program can be done through educated teachers, peer leaders or health workers. Numerous studies conducted in recent years confirmed the efficacy of LST program in a reduction of the prevalence of use of tobacco, alcohol and illegal drugs in 50 to $87 \%$ compared to the control group. In the last years, a version of LST program has been developed for even younger children (children aged three to five, which is from fourth to sixth grade of elementary school) which proved to be efficacious in the reduction of tobacco and alcohol use.

SF program (The Strengthening Families Program) is a selective, multicomponent preventive program aimed at families under risk and 
was initially developed with an aim to provide help to parents who abuse drugs, as to improve their parenting skills and reduce risks that might influence children in a negative manner. SF program is designed with the aim to increase resistance and reduce risk factors for the development of behavioral, emotional, academic and social problems in children aged three to sixteen and it consists of three components. The first component includes training parental skills program, aimed at teaching parents skills in increasing the wished for behavior in children, through rewards, clear communication, efficient discipline, problem solving and education on the use of substances. The second component consists of training children skills program, with the aim to help children accept parental rules, develop and improve skills of efficacious communication, problem-solving, resisting to pressures of peers, social skills, and to understand their own feelings and consequences of substance use. The third component contains family skills training program, focused at involving families in structured activities, practicing therapeutic games, learning communication skills, conducting efficacious discipline, mutual support to positive behavior, organizing family meetings, and planning common family activities. The program is being applied through fourteen sessions lasting two hours. Parents and children are separately included during the first hour, and during the second hour, they are included in the program together. Research results suggest that involving families in associated family support groups increase generalization and utilization of learned skills. According to research results this program results with a decrease of family conflict, behavioral issues at youngsters, aggressiveness and drug abuse, as well as an increase of moral skills in youngsters, parental skills and family communication and organization. SF program is linguistically and culturally adapted and evaluated for different ethnic groups in the USA and many other countries including Australia, Austria, Canada, Denmark, France, Italy, Norway, Portugal, Russia, Spain, Sweden, and Slovenia.

Project TND (Project Towards No Drug Abuse) is indicated, school aimed preventive intervention designed for adolescents, aged fourteen to nineteen. It was initially designed for youngsters who attend alternative high schools (schools for pupils with poor academic results, discipline issues, negative attitudes toward school, and pupils under greater risk for drug use and whose parents abuse drugs). Afterwards, it was adapted and evaluated for the population of adolescents under high risk in traditional schools. Taking into consideration developmental issues which older adolescents 
face with, especially the ones under drug abuse risk, the program has the aim to prevent progression of drug use towards the abuse. Main component of TND program is the curriculum of twelve interactive sessions that involves play, exercise, role play, video materials, and written homework, conducted by teachers or health educators through group discussions in classes. Those sessions include motivational activities, correction of false beliefs, social skills training, skills in making decisions and self-control skills targeting use of tobacco, alcohol, marijuana and "heavy" drugs, and behaviors related to violence, such as carrying weapon. Project TND was rigorously evaluated in several experimental studies. Results confirmed its efficacy in significant reduction of severe alcohol use compared to control groups.

\section{CONCLUSION}

In the last decades utilization of more efficacious evidence-based programs became "golden" standard of highly professional practice in the area of prevention. Namely, a number of well designed, randomized controlled studies support the hypothesis that substance abuse among youngsters in a significant manner can be prevented by implementation of tested programs and policies. These programs are aimed at a decrease of individual, family and pear risks, as well as community risks that are responsible for the beginning of substance use and its progression towards abuse. They also increase the influence of protective factors and processes. In the end, it is important to accent that proven efficacious preventive programs can be cost-effective because of research point out that each dollar invested in prevention saves up to ten dollars invested in treatment of disorders caused by substance abuse. 


\section{REFERENCES}

Arthur, M.W., Hawkins, J.D., Pollard, J., Catalano, R.F, \& Baglioni, A.J. (2002). Measuring Risk and Protective Factors for Substance Use, Delinquency, and Other Adolescent Problem Behaviors: The Communities That Care Youth Survey. Evaluation Review, 26, 575-601.

Bandura, A. (1977). Social learning theory. Englewood Cliffs, NJ: PrenticeHall.

Bloom, M., \& Gullotta, T.P. (2009). Primary Prevention in Adolescent Substance abuse. In C.G. Leukefeld, T.P. Gullotta, \& M. StatonTindall (Eds.). Adolescent Substance Abuse. Evidence-Based Approaches to Prevention and treatment (pp. 155-170). Springer.

Botvin, G.J. (2000). Preventing drug abuse in schools: Social and competence enhancement approaches targeting individual-level etiological factors. Addictive Behaviors, 25, 887-897.

Botvin, G.J., \& Kenneth, W.G. (2006). Drug Abuse Prevention Curricula in Schools. In Z. Sloboda \& W.J. Bukoski (Eds.). Handbook of Drug Abuse Prevention (pp 45-74). New York: Kluwer Academic/Plenum Publishers.

Catalano, R., Haggerty, K., Hawkins, J., \& Elgin, J. (2011). Prevention of substance use and substance use disorders: Role of risk and protective factors. In Y. Kaminer \& K.C. Winters (Eds.), Clinical manual of adolescents substance abuse treatment (pp.25-63). Arlington, VA: American Psychiatric.

Cooney, S.M., Huser, M., Small, S., \& O’Coonor, C. (2007). Evidencebased programs: An overview, What Works, Wisconsin-Research To Practice Series, Issue 6.

Coughlan, B.J., Doyle, M., \& Carr, A. (2006). Prevention of teenage smoking, alcohol use and drug abuse. In A. Carr (Eds.) Prevention: What Works with Children and Adolescents? A Critical Review of 
Psychological Prevention Programmes for Children, Adolescents and their Families (pp. 267-286). Taylor \& Francis e-Library.

Ennett, S.T., Ringwalt, C.L., Thorne, J., Rohrbach, L.A., Vincus, A., Simons-Rudolph, A., \& Jones, S. (2003). A comparsion of current practice in school-based substance use prevention programs with meta-analysis findings. Prevention Science, 4, 1-14.

Fagan, R. (2006). Counseling and Treating Adolescents With Alcohol and Other Substance Use Problems and Their Families. The Family Journal, 14, 326-333.

Forman, S.G., Olin, S.S., Hoagwood K.E., Crowe M., \& Saka, N. (2009). Evidence-Based Interventions in Schools: Developers' Views of Implementation Barriers and Facilitators. School Mental Health, 1, 26-36.

Foxcroft, D.R., \& Tsertsvadze, A. (2011). Universal school-based prevention programs for alcohol misuse in young people. Cochrane Database Systematic Reviews, 5, CD0091 13.

Griffin, K.W., \& Botvin, G.J. (2010). Evidence-Based Interventions for Preventing Substance Use Disorders in Adolescents. Child Adolesc Psychiatr Clin N Am. 19 (3), 505-526.

Hallfors, D., \& Godette, D. (2002). Will the 'Principles of Effectiveness' improve prevention practice? Early findings from a diffusion study. Health Education Research: Theory \& Practice, 17, 461-470.

Hawkins, J.D., Catalano, R.F., \& Arthur, M. (2002). Promoting sciencebased prevention in communities. Addictive Behaviors, 90 (5), 1-26.

Hawkins, J.D., Catalano, R.F., \& Miller, J.Y. (1992). Risk and Protective Factors for Alcohol and Other Drug Problems in Adolescents and Early Adulthood: Implications for Substance Abuse Prevention. Psychological Bulletin, 112 (1), 64-105.

Hemovich, V., Lac, A., \& Crano, W.D. (2012). Understanding Early-Onset and Alcohol Outcomes among Youth: The Role of Family Structure, Social Factors, and Interpersonal Perceptions og Use. Psychol Health 
Med; 16 (3), 249-267. Retrieved from

http://www.publicsafety.gc.ca/cnt/rsrcs/pblctns/sclbsd-drgbs/sclbsd-drgbseng.pdf

Hunsley, J., \& Lee, C.M. (2010). Introduction to Clinical Psychology: An Evidence-Based Approach. John Wiley \& Sons, Inc.

Jessor, R., \& Jessor, S.L. (1977). Problem behavior and psychosocial development: A longitudinal study of youth. New York: Academic Press.

Jochman, K., \& Fromme, K. (2010). Maturing out of substance use: The other side of aetiology. In L.Scheier (Ed.). Handbook of drug use aetiology: Theory, methods, and empirical findings (pp. 565-578). Washington, DC: American Psychological Association.

Kandel, D. (2002). Stages and pathways of drug involvement: Examining the gateway hypothesis. Cambridge University Press; New York.

Kyler, S. J., Bumbarger, B. K., \& Greenberg, T. (2005). Technical assistance fact sheets: Evidence-based programs. University Park, PA: Penn State University, Prevention Research Center for the Promotion of Human Development. Retrieved from

http://prevention.psu.edu/pubs/docs/EBP_factsheet.pdf

Lopez, A.D. (2006). Global burden of disease and risk factors. Washington, DC: Oxford University Press.

Mrazek, P.J., \& Haggerty, R.J. (1994). Reducing risks for mental disorders. Washington, DC: National Academy Press.

National Crime Prevention Centre (NCPC) (2009). School-Based Drug Abuse Prevention: Promising and Successful Programs. Retrieved from:

http://www.publicsafety.gc.ca/res/cp/res/2009-01-drg-abs-eng.aspx

National Institute on Drug Abuse (2003). Preventing Drug Use Among Children and Adolescents: A Research-based Guide for Parent, Educators, and Community Leaders (2nd ed.). Washington, DC: U.S. Department of Health and Human Services. 
Newcomb, M.D., \& Locke, T. (2005). Health, Social, and Psychological Consequences of drug Use and Abuse. In Z. Sloboda (Ed.). Epidemiology of Drug Abuse. Springer; New York (pp. 45-59).

Schinke, S.P., Botvin, G.J., \& Orlandi, M.A. (1991). Substance abuse in children and adolescents. Evaluation and Intervention. Newbury Park, Calif: Sage.

Sloboda, Z. (2009). School Prevention. In C.G. Leukefeld, T.P. Gullotta \& M. Staton-Tindall (Eds.). Adolescent Substance Abuse. Evidence-Based Approaches to Prevention and treatment (pp. 191-211). Springer.

Stigler, M.H., Neusel, E., \& Perry, C.L. (2011). School-Based programs to Prevent and Reduce Alcohol Use Among Youth. Alcohol Research \& Health, 34(2), 157-162.

Substance Abuse and Mental Health Services Administration, SAMHSA (2015). National registry of Evidence-based Programs and Practices (NREPP). Retrieved from www.nrepp.samhsa.gov/Aboutnrepp.aspx/.

Sussman, S., \& Ames, S.I. (2008). Drug Abuse. Concepts, Prevention, and Cessation. Camridge University Press.

Swendsen , J., Burstein, M., Case, B., Conway, K.P., Dierker, L., He, J., \& Merikangas, K.R. (2012). Use and Abuse of Alcohol and Illicit Drugs in US Adolescents. Results of the National Comorbidity SurveyAdolescent Supplement. Archives of General Psychiatry, 69(4), 390398.

Thomas, R.E., McLellan, J., \& Perera, R. (2013). School-based programs for preventing smoking. Cochrane Database of Systematic Reviews, (4), CD001293.

Ysseldyke, J., Burns, M., Dawson, P., Kelly, B., Morrison, D., Ortiz, S.,... Telzrow, C. (2006). School psychology: A blueprint for training and practice III. Bethesda, MD: National Association of School Psychologists. 